\title{
Familiarizing pupils 4-6 years old with forms of spatial representation. The use of photography as an auxiliary tool
}

Konstantinos Zacharos, Maria Kilia, Konstantinos Ravanis

University of Patras, Department of Educational Sciences and Early Childhood Education, Rion-Patras, 26500, Greece

\section{ABSTRACT}

One of the research and teaching interests in early childhood education is the understanding of spatial concepts and orientation in space. The present study, which is a pilot study, attempts to investigate whether pre-school students can recognize familiar locations in photographs, the locations being in this case parts of their schoolyard, and furthermore if they can extract information from the photos and orient themselves in space. The sample of the study was made up of 18 children aged 4 to 6 years from a Greek kindergarten. The subjects of the sample underwent individual interviews. Qualitative analysis of the findings showed that photographs may be a useful tool for teaching spatial concepts such as those which concerned us in this investigation.

\section{Indexing terms/Keywords}

Spatial Concepts, Representations, Photography, Early Childhood Education

\section{Academic Discipline And Sub-Disciplines}

Early Childhood Education, Mathematics and Science Education

\section{Council for Innovative Research}

Peer Review Research Publishing System

\section{Journal: Journal of Social Science Research}

\author{
Vol.4, No.1 \\ editor@jssronline.com \\ www.cirworld.com, www.jssronline.com
}




\section{INTRODUCTION AND THEORETICAL FRAMEWORK}

The development and use of iconic representations of real space such as maps and models is interwoven into modern culture. This fact is also evident in the field of education, where various forms of iconic representations and symbols are used (Ravanis \& Papamichaël, 1995; Ravanis, Papamichaël \& Koulaidis, 2002; Pantidos et al., 2008; Zacharos \& Koustourakis, 2011; Siakalli \& Zacharos, 2012). Also, the interest in iconic representations is shown by the multitude of studies which explore the ability of pupils to understand and use forms of external representations even in early childhood education (for example: Piaget \& Inhelder, 1956; Bishop, 1980; Liben \& Downs, 1993; Blades et al., 1998; DeLoache, 2000; Clements \& Sarama, 2009).

The ability to transition from three-dimensional objects to two-dimensional representations such as shapes, drawings, pictures, etc. and the process of reading two-dimensional representations to recognise information relevant to threedimensional space is a complex cognitive process, which education seeks to reinforce by the adoption of appropriate didactic intervention. Transformations from three dimensions (3D) to two (2D) and the reverse process from 2D to 3D require the mental reorganisation of spatial relationships, projections, dimensions and all other relevant data in such a way as to facilitate matching the real objects with the represented ones.

In this study our interest is focused on the ability of pupils in early education aged from 4 to 6 to use a relatively easily "read" form of representation, the photograph, to extract information relevant to the space it represents. The photographs used in the study are of the schoolyard belonging to the pupils who participated in our study. In the presentation of the study which follows we make a brief overview of the bibliography which refers to findings related to the ability of pupils, especially in the early stages of education, to understand and interpret external representations such as maps and photographs, formulate the research questions and describe the research methodology. Finally, we analyse the research questions and comment upon them.

Modern science emphasises forms of representation which are characterised as "external representations" (e.g. Goldin \& Kaput, 1996). Examples of these are pictures, maps, diagrams, symbols, charts and three-dimensional models used in the sciences, etc. Each type of external representation describes a real space, the so-called reference space, with which the representation is linked.

A child's ability to perceive that a representation refers to a real object appears roughly at the age of three, accompanied by the ability to understand the function of symbols (Piaget \& Inhelder, 1956; DeLoache \& Marzolf, 1992). The similarity which each representation has with the original and the degree to which the geometric ratios and relationships map to the original are properties which help the child to understand that the representation symbolizes something real. Pictures and photographs in particular are more easily understood by children as representations of real space (DeLoache, 2000), because they have clarity (representational specificity), as opposed to sketches or drawings which often depict wider classes of objects and illustrate general and abstract ideas (DeLoache \& Marzolf, 1992).

The child builds space in his mind by initially using his own body as a frame of reference. Afterwards, the reference is transposed outside his body to an externally-based system (Bishop, 1980; Clements and Sarama, 2009). In a further level of the child's development of spatial concepts he/she is able to identify locations when given external points of reference (Clements \& Sarama, 2009).

The use of a spatial representation for the extraction of information in order to identify locations in real space is based on coordination of attention in many axes, and mainly in the horizontal and vertical, referring to an orthogonal coordinate system (Clements \& Sarama, 2009). Furthermore, the identification of an object among other similar ones requires the mastering of additional abilities such as the recognition of the relative location of objects.

Research has shown that children below three have difficulty in using scale models to find a hidden object in an area greater than a classroom when represented by a photograph or map. They also find it hard to locate an object which is in a different direction than their current orientation. However, older children around four to five show higher abilities in similar tasks (Liben \& Downs, 1993; Blades et al., 1998; DeLoache, 2000; Clements \& Sarama, 2009).

The similarity between object and representation significantly helps children to successfully complete related tasks (e.g. DeLoache, 2000; Plester et al., 2002). In particular, children can recognise photographs, the subject of this article, as a representation of space from a very early age and even at pre-school age are able to relate photographs to real space. Difficulties arise in cases when the perspective of the photographs is different from that of the child: in these cases the children find it hard to identify the relative positions of the objects in space (Newcombe \& Huttenlocher, 1992; DeLoache et al., 1998; DeLoache, 2000).

In the present paper we investigated the abilities of pupils in early childhood education to "read" photographs which depict areas the size of a compound containing the school building and the schoolyard. Our research is qualitative and focuses on exploring the possibilities of the use of photographs as a source of information relating to space in kindergarten in Greece. We were particularly interested in the ability to understand perspective in photographs and the identification of locations where the abilities to distinguish the relative positions of objects and the use of comparisons are required $(2 \mathrm{D} \rightarrow 3 \mathrm{D})$.

In addition, our intention was to investigate the reverse process, the ability of pupils in our sample to note on the photographs the positions of objects which they were shown in real space $(3 D \rightarrow 2 D)$. The relationship between children and photographs seems to be changing in recent years, since children learn to take photographs with mobile phones or digital cameras in early childhood. 
The particular purpose of this study is to investigate the following questions:

- if Greek kindergarten pupils aged 4 to 6 can recognise that specific photographs they are given represent locations in real space,

- if they can identify the position from which the specific photographs were taken,

- if they can point out on the photograph where they are at the moment the interview is being conducted,

- if they can mark on photograph representations the positions of objects they are shown in real space,

- finally, if with limited ad hoc teaching interventions we can support limited transformations in the children's thought processes, in order to obtain first indications of the possibility of formulating specially designed teaching interventions.

\section{METHODOLOGY}

\section{The procedure}

As stated earlier, the present study is qualitative and investigates the abilities of children to to use photographs as a source to extract information about real space. Specifically, the part of the study presented in this article used photographic representations of a kindergarten schoolyard. The photographs were taken from above, from the rooftop terrace of the kindergarten with a diagonal perspective. The real dimensions of the represented space, that is, the schoolyard, were of a scale that Plester et al. (2002) describe as a large area.

The suggested tasks were put in a pedagogical framework (Zacharos, Antonopoulos \& Ravanis, 2011) of a supposed hunt for hidden treasure to pique the children's interest. The tasks used, in accordance with the classifications of Plester et al. (2002), included three kinds of locations:

The first kind had distinctive places, that is, ones which were recognisable from specific topological features, unique both in the photograph and in the real space. In this case the purpose of the tasks was to find a unique object in the space, the object in question requiring recognition of the relationships between the unique object in the representation (photograph) and the real object in the space.

The second kind of location contained nondistinctive places and required the identification of an object from many other similar ones. Finding the object was based on the ability to coordinate the relative positions of the objects in space.

Finding the third kind of location required the ability to calculate the relationships between the distances in the space, that is to say the relationships in the photograph had to be re-evaluated in real space.

\section{The sample}

The sample used in the study consisted of eighteen pupils, of whom twelve had an average age of around 5.3 years (hereafter referred to as Subjects S1-S12) and six of average age 4.5 years (henceforth TS13-S18). They were all pupils at an urban Greek state-funded kindergarten. It should be noted that in Greece the kindergarten involves two years of schooling ( $\mathrm{K} 1$, the children of an average age of 4.5 years old, and $\mathrm{K} 2$, the children of an average age 5.3 years old). In most of the kindergarten classes, the K1 and K2 children are grouped together in one class.

When the study was performed the class teacher had not previously referred to forms of spatial representation and had not used photographs as educational material in a framework similar to that of the study.

Individual interviews using photographs and the specific tasks were recorded on video and used to collect the empirical data. Our analysis was based on the recorded material and the researchers' notes.

\section{Research questions and tasks}

The general purpose of the study is served by five research questions extended using four tasks. In each task we proceed, according to the progress of the interview, to restricted local interventions having the properties of teaching interventions, with the purpose of modifying and/or improving the pupils' estimates.

The research questions and associated tasks are summarily presented in Table 1 and are the following:

First research question (from two dimension to three $-2 \mathrm{D} \rightarrow 3 \mathrm{D}$ ): Can the children recognise what the photographs depict?

Second research question $(2 \mathrm{D} \rightarrow 3 \mathrm{D})$ : Can the children recognise the elevated point from which the photograph was taken, that is, the possible position of the photographer?

Third research question (from three dimension to two - 3D $\rightarrow 2 \mathrm{D}$ ): Can the children point out on the photograph the location they are in at the time of the interview?

First task: The investigation of the three first research questions was done using an introductory task, where photographs with diagonal projection were used (photographs 1 and 2) which are considered easier to "read" than photographs with a vertical projection (Plester et al. 2002). 
The children are individually led into the schoolyard, where they are presented with the two photographs taken with different perspectives, in order to see if there is a difference in their perception of the representation of space.

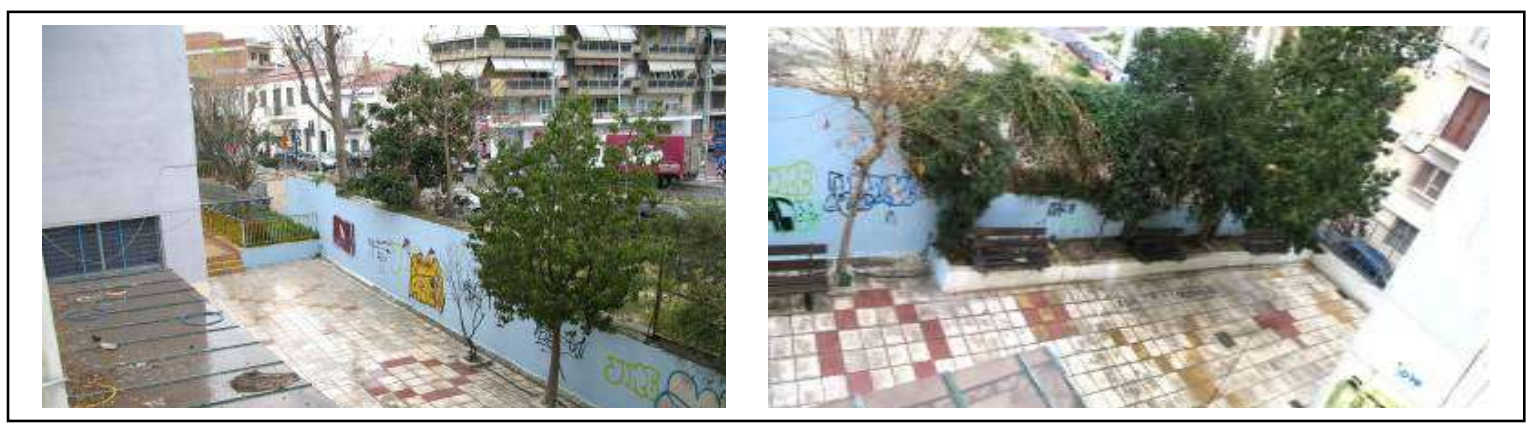

Photographs 1 and 2. Representations of the schoolyard

Afterwards the following questions, related to the first research question, were asked for each photograph:

- "What does the photograph show?"

- "Do you know this place? Does it remind you of anything?"

Answers such as "Here", "Our school", "Our yard" etc. were considered correct, showing that the children perceive that the photograph is of the kindergarten schoolyard.

To investigate whether the children understood the vantage point at which the photographs were taken (second research question) the following questions were asked:

- "Where was the photographer sitting when the photograph was taken?", or

- "Where would we sit if we wanted to take the same photograph?"

- "Which photograph would we be in if the photographer took a picture of us now?"

Finally, to find whether the children are capable of pointing out on the photographs the location they are in at the time of the interview, we asked the following question (third research question):

- "Can you show me on the photograph exactly where we are sitting now?"

Fourth research question $(2 \mathrm{D} \rightarrow 3 \mathrm{D})$ : Can the children find hidden objects in real space using the photograph as a source of information?

The investigation of the fourth research question was performed with the second and third task. The second task involved a location which was in the class of distinctive places, whereas in the third task the location was in the class of nondistinctive places. The two tasks are described in more detail below.

Second task - Finding a distinctive object and calculation of relationships: This particular task requires the ability to relate an object in the photograph with the corresponding object in real space and the ability of the children to take into account the scale relationships in the photograph when transformed into real space.

In accordance with the way the tasks were presented, there is a dot on the photograph of the schoolyard which marks the location of the hidden treasure, which the children are then asked to find. The photograph used was photograph 1 of the first task. The location of the hidden object was the kerb at the bottom of photograph 1 at a distance of two-thirds from the left edge of the kerb. The particular kerb was considered as a distinctive place and furthermore the child had to compare the scale of the photograph with that of the real space to be able to accurately indicate the hidden box in real space.

With regard to the ability to compare an object with other objects, an answer where the child pointed out the kerb or headed towards it was considered correct. In addition, before the child looked behind the kerb to find the hidden object, he/she was asked to show the exact location of the object.

Third task - Finding a distinctive object using its relative position to other objects: The goal of this task was to investigate the child's ability to find the second type of location, which required him/her to calculate the relative positions of objects.

After finding the hidden box in the previous task either by themselves or with the help of the researcher, they were taken once more to the centre of the schoolyard to open the box. Inside the box was photograph 2, with the second location marked on it, which was one of the benches in the schoolyard (distinctive object among similar objects).

Fifth research question $(3 \mathrm{D} \rightarrow 2 \mathrm{D})$. When the children hide objects in real space, can they then point out their locations on the photograph?

The exploration of the fifth question was performed with the fourth task. 
Fourth task: The goal of this task was the exploration of the children's ability to note the positions of locations in real space on the photograph, in other words a transformation from real space (3D) to its representation in two dimensions (2D).

Again in accordance with the way the tasks were presented, the children were urged to become pirates and to hide the treasure in a different part of the schoolyard. Furthermore they were asked to give information via the photographs (to mark the location on the photographs) in order to help their fellow-pupils to find the treasure.

It was suggested to the students that they hide the treasure along the schoolyard wall, specifically behind the third tree in the row of four trees in photograph 3 . We wanted thus to investigate the ability of the children to relate objects in real space with objects in the photograph, something which requires the identification of the relative position of the object from among other similar ones. Essentially in this case the object they have to locate is not the box but the particular tree in the row of trees.

This task was given in two forms: in the first case the photograph was taken according to the viewpoint of the pupils, whereas in the second case it was taken with the opposite viewpoint.

\section{RESULTS}

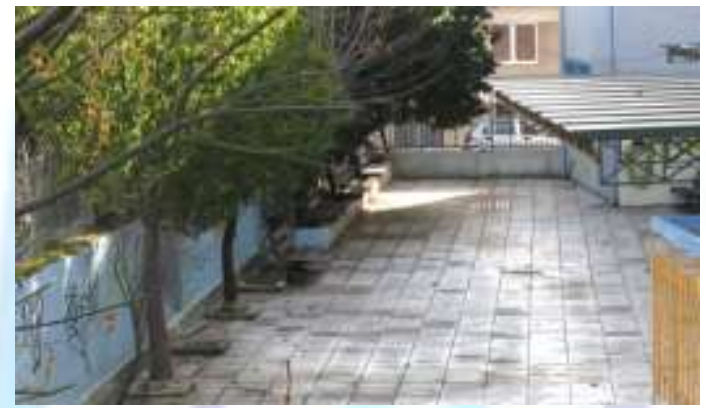

Photograph 3 - Fourth task

\section{From two-dimensional space to three-dimensional}

\section{First task}

First research question $(2 D \rightarrow 3 D)$ : We found that all the children recognised that the photographs were representations of the particular area of their school: part of the schoolyard.

Second research question $(2 \mathrm{D} \rightarrow 3 \mathrm{D})$ : In this case the children were asked to show the vantage point of the photographer. Answers which pointed out the perspective of the photograph or the area from which the photograph was taken were considered correct.

The children's answers to this question were classed in categories as follows:

i. Six children from age group K2 and 1 child from K1 correctly pointed out the area from which the photograph was taken. They understood that the photograph was taken from "somewhere high up" and tried to find the exact location by asking the researcher if he went up to a window. Indeed, in some cases children climbed onto benches and pointed out the area from which the photograph was taken (Extract 1).

Extract 1. Identification of the photographer's vantage point and pointing out the correct viewpoint.

$R$ (researcher): Where do you think the photographer was when he took this photograph (photograph 1)? If we wanted to take the same photograph, where would we go?

S5(subject 5): He sat here (climbs onto the bench and points in the correct direction) but he was somewhere high up.

$R:$ Why do you think he was high up?

S5: Because from up there you can see all the trees but from here (indicates the ground level of the yard) we can't see them all.

$R$ : Where was the photographer when he took this (shows photograph 2) picture?

S5: Probably at the window (points to the window).

$R:$ And where was he looking?

S5: Towards the stairs (the stairs leading to the schoolyard exit).

R: Why do you think he was looking at the stairs?S5: Because you can see that (shows the top part of the shelter visible in the photograph).

ii. The second category has the answers of the children (4 children from age group K2 and 2 child from K1) who, whilst they identified the correct direction from which the photograph was taken, thought that it was taken at ground level. 
Teaching interventions

At this point the researcher helps the child with appropriate interventions. Specifically, he draws their attention to elements of the photograph which are not visible from ground level, such as the tops of the trees and the top of the shelter. Then those particular subjects are asked to guess the probable vantage point from which the photograph was taken. In these cases 3 children from age group $\mathrm{K} 2$ and 1 child from $\mathrm{K} 1$ improve and correct their answers, as in the following dialogue extract (Extract 2).

\section{Extract 2. Finding the photographer's location.}

The subject correctly shows the direction from which the photograph was taken, but places the photographer at ground level.

R: Why do you think the photographer was here (at the position in the schoolyard indicated by the subject)?

S14: Because we would take the same photograph.

$R$ : What's this here (we show the shelter roof in the photograph)?

S14: It's that up there (shows the shelter).

$R: Y e s$, it's the shelter. How can we take a photograph that shows the top of the shelter?

S14: We have to get up high (points in the correct direction).

iii. Finally, the subjects ( 2 children from age group $\mathrm{K} 2$ and 3 child from $\mathrm{K}$ ) which had difficulty identifying both the direction from which the photograph was taken and the vantage point, despite the researcher's interventions, are classed in another category.

Third research question $(3 \mathrm{D} \rightarrow 2 \mathrm{D})$. Here the children were asked to point out on the photographs the position they were in when the relevant question was asked. It should be noted that only the second photograph showed the location.

The following categories of answers were derived from analysing the children's responses.

i. The first category contains the children ( 6 children from age group K2 and 2 children from K1) who were able to correctly point out their position on the photograph, with sound explanations using nearby objects as landmarks, such as "because we are next to that bench in the photograph", or "that dead tree is next to us", etc. .

ii. In the second category are the children ( 3 children from age group K2 and 2 children from K1) who chose the correct photograph but could not correctly point out their exact position on it. In these cases although the children used objects as landmarks, they made incorrect estimates of the relative locations of these objects and themselves. For instance, they believed that the deciduous tree in the second photograph was on their left whereas in reality it was on their right.

Teaching interventions

In the previous cases the researcher intervened and invited the children to role-play and "follow the photographer's eye". This particular activity helped the children in this category to eventually point out their position on the photograph.

iii. The third category contains the children ( 3 children from age group K2 and 2 children from K1) who could not use landmarks in the space to point out their position on the photograph.

\section{Second task}

Fourth research question $(2 \mathrm{D} \rightarrow 3 \mathrm{D})$. Finding a specific object and evaluating relationships.

Here the children were initially asked to point out from their current position (in the centre of the schoolyard) the location where an object was hidden. Following this they were asked to point out the exact position of the object.

All the children pointed out the kerb behind which the object was hidden. However the following categories resulted from the children's answers to the problem of finding the exact location.

i. The first category ( 8 children from age group $\mathrm{K} 2$ and 1 child from $\mathrm{K} 1$ ) showed the correct spot on the kerb where the hidden object was.

ii. In the second category are the children (4 children from age group K2 and 5 children from K1) who chose the wrong spot, usually the middle of the kerb or one of its endpoints.

Teaching interventions

The cases where exact position was chosen wrongly, the researcher intervened with appropriate questions, focusing the child's attention on the distances the spot on the photograph had from the endpoints of the kerb (Extract 3 ). The interventions led 2 children from age group K2 and 2 children from K1 to correct their mistaken answers.

\section{Extract 3. Judging relationships}

The subject (subject 10) points out the kerb, but not the precise position, saying that the object is "somewhere there".

$R$ : Can you show me exactly where it is?

$S:$ There (shows the centre of the kerb).

$R$ : Can you show me (shows the photograph of the kerb) where the middle is here?

$S$ : here (shows the middle of the kerb).

$R$ : Where is the right-hand part?

459 | P a g e 
The subject shows the right-hand part of the kerb.

$R$ : The left-hand part;

The subject shows it correctly.

$R:$ Now tell me, is the spot on the left, the middle, or the right?

$S$ : Here on the right (shows the spot in the photograph).

$R$ : That is (on the kerb in the schoolyard) where the object is?

$S$ : There (shows the correct area).

\section{Third task}

Fourth research question $(2 \mathrm{D} \rightarrow 3 \mathrm{D})$. The purpose of this task is to find a distinct object from among other similar objects. The manner in which the children responded to this activity led to the following categories:

i. The first class contains 9 children from age group $\mathrm{K} 2$ and 3 children from $\mathrm{K} 1$ who were able to compare the spatial relationships, went to the correct bench and found the hidden object immediately.

ii. Finally, the second class contains those ( 3 children from age group K2 and 3 children from K1) children who did not manage to compare the spatial relationships and went to the wrong bench.

Teaching interventions

In these cases the researcher's teaching intervention, shown in Extract 4, helped the children to correct their wrong answers. In this way, 2 children from age group $\mathrm{K} 2$ and 2 children from $\mathrm{K} 1$ corrected their initially incorrect answers and pointed out the correct bench.

Extract 4. Teaching intervention to help find a distinct object from among other similar objects

In the part of the schoolyard shown in the photograph there are five benches in total and the hidden object was placed on the third bench, according to the perspective of the photograph. Subject S13 points out the fourth bench.

$R$ : Why do you think the treasure is there?

S13: That's what I think.

R: How many benches are on this side of the yard (shows the side of the yard)?

S13: (Counts) One, two, three, four, five. Five benches.

$R:$ And on which bench in the row is the treasure?

S13: On the fourth. Miss, can I show you where it is in the photograph?

R: Yes.

S13: (Counts on the photograph to the fourth bench) Here, it's hidden on this bench!

\section{Fourth task}

Fifth research question $(3 D \rightarrow 2 D)$. Here we investigate whether the children can point out on the photograph the position of an object we had hidden in the yard.

This task required the location of the relative position of an object from among similar ones, in two different variations: in the first the photograph was taken in agreement with the pupils' viewpoint, whereas in the other it was taken in from the opposite viewpoint. In each case answers in which the pupils marked the correct position on the photographs were considered as correct.

Photograph taken in agreement with the pupils' viewpoint. In this research question the children's answers were placed into categories as follows:

i. In the first category are the children who gave correct answers ( 8 children from age group K2 and 2 children from K1). The answers were of two main forms: Some children immediately marked the position, thus indicating an ability to use the particular form of representation as well as a sufficient grasp of the space and its relative dimensions. Another form of answer was based on counting the trees in real space and then repeating this practice on the photograph.

ii. The second category has the children who either gave wrong answers or stated that they did not know the answer. In these cases the researcher intervenes in a similar way to that described in Extract 4, with the result that 3 children from age group $\mathrm{K} 2$ and 2 children from $\mathrm{K} 1$ then gave successful answers.

Photograph taken in the opposite sense from the pupils' viewpoint. The correct answer to this question is particularly difficult for children of this age group (Piaget, \& Inhelder, 1956), since it presupposes the ability of children to decentrate from their own perspective and understand the viewpoint depicted in the photo. As a result very few pupils gave correct answers (4 children from age group K2). In these cases the pupils went of their own accord to the other side of the yard in order to see from the viewpoint of the photograph.

In the cases where incorrect answers are given, the researcher intervenes as shown in Extract 5, with the result that 3 children from age group $\mathrm{K} 2$ and 1 child from $\mathrm{K} 1$ corrected their answers.

Extract 5. Researcher's interventions for the fourth task, in the case where the photograph taken in the opposite sense from the pupils' viewpoint

$R$ : Where do you think the photographer who took this photograph was?

S5: I don't know

460 | P a g e 
R: If you had taken this photograph, where would you have been?

S5: (Thinks)... There (shows the other side of the yard).

$R$ : Let's go there and see where we'll put the mark on the photograph.

...Where is the tree where we put the treasure?

S5: There (shows the correct tree).

$R$ : Where will we put the mark on the photograph?

The subject counts the trees in the real space and then does the same for the trees in the photograph.

These particular interventions improved the answers of the children with the result that 5 children from age group K2 and 1 child from $\mathrm{K} 1$ gave correct answers.

Table. Classification of answers to Research Questions.



\section{CONCLUSION AND DISCUSSION}

In this paper we concerned ourselves with forms of spatial representation. The space chosen for the research was part of the kindergarten schoolyard, and photographs of the particular area were used as forms of representation. The purpose of the research was to investigate whether the pupils in our sample were able to recognize which area was represented by the photographs, to locate the vantage point of the photographer when the photographs were taken and also using a photograph as a guide, to find the locations of objects in real space. Furthermore, the reverse process was investigated, namely the ability of the children to note on a photograph the location of an object given the knowledge of its location in real space. 
The investigation of the first research question showed that the subjects in our sample were capable of recognising that the photographs we showed them were of a space familiar to them. This fact reveals that the subjects in question understand the relationships between the reference space and its symbolic representation (in this case the photograph), something that is perceived in a holistic manner (Downs et al., 1988).

In the second research question correct responses were observed for approximately half of the pupils. These pupils could identify the probable vantage point of the photographer and develop a processed argument, as in Extract 1, where the subject points overhead to the area from where the photograph was taken and explains "Because from up there you can see all the trees but from here (the ground level of the yard) we can't see them all". For the children who answered wrongly here, the researcher's teaching interventions improve the answers for the majority (Extract 2).

The third research question asked the subjects to choose which of two photographs depicted their location at the time the interview took place. The majority of the younger pupils and half of the older ones had difficulty choosing the correct photograph and explaining their choice. However, the researcher's suggestion that the children participate in a role-playing game in which they were called upon to see the area, the relative locations of objects and the perspective of the photographs in the role of the photographer, facilitated the correct choice of photograph and a correct explanation of the choice made.

In the fourth research question (second task), although all the children initially pointed out the rough area where the hidden object was, there were difficulties, especially with the younger pupils. Many of the subjects who gave correct answers seem to have developed the skill of finding locations via a holistic perception of space.

The difficulties pupils in category $\mathrm{K} 1$ have in dealing successfully with similar problems successfully is noted in the relevant bibliography (e.g. Pebone et al., 2001; Plester et al., 2002: Clements \& Sarama, 2009). Truly, the ability to use relationships as required for this specific task presupposes that the child is able to mentally acquire the source reference (the photograph), to assign its relevance to the portrayed object (the kerb), to assign the relative positions of the objects in each case and to reproduce a comparable process to find the location. The researcher's discussion with the children about the relative dimensions in the photograph helped the subjects point out the actual position in real space (Extract 3).

For the fourth research question (third task), which required the pupils to find a location in space from among other similar ones, the majority of the pupils gave successful answers, often accompanied with correct reasoning. In the cases where incorrect answers were given, the researcher's interventions as recorded in Extract 4, helped the pupils improve their answers.

The findings which result from the fifth research question (fourth task - photograph from the pupil's viewpoint) show that the majority of the pupils in category K2 successfully handled the relevant task which required transformation from 3D to 2D space. The pupils had more difficulties in the cases where the photograph's viewpoint was opposite from theirs (fifth research question - photograph with viewpoint opposite from that of the pupils). The specific task requires the pupils to activate mental abilities such as the capability to decentrate from their own viewpoint and "see" from the viewpoint of a third party, in this case from the perspective of the photograph or, differently, from that of an imaginary photographer. The participation of the children in role-playing games when prompted to do so by the researcher helped them understand the different perspective of the photographs and adopt improved and better-reasoned answers (Extract 5).

Despite the fact that these tasks were not expressly designed to teach the children the use of the photograph as a source of information about space or to accustom them to "read" the photograph, the teaching interventions of the researcher when they failed (see Extracts 3, 4 and 5), helped the subjects give correct answers. This fact reveals the teaching potential that could be created by systematic and well-planned educational activities which could be incorporated into the preschool curriculum in order that the pupils become accustomed to that particular representation of space.

In summary, we conclude that this pilot research paper shows that the spatial knowledge and spatial ability (Kolukisa \& Ocal 2007) of the pupils in our sample is encouraging enough to warrant systematic research activity into spatial concepts in preschool education. The object of this prospective research is the design, implementation and evaluation of a programme to teach spatial concepts (Zacharos, 2005, 2006; Ravanis, Zacharos \& Vellopoulou, 2010) and specifically to develop the ability of preschool children to use iconic representations of spaces. The familiarisation of the children with the conventions (signs) used in forms of representation such as maps and diagrams should be part of the interests addressed by this educational research.

\section{REFERENCES}

[1] Bishop, A. J. (1980). Spatial abilities and Mathematics achievement-A review. Educational Studies in Mathematics, 11, 257-269.

[2] Blades M., Blaut J., Davizeh Z., Elguea S., Sowden S., Soni D., Spencer C., Stea D., Surajpauli R. \& Uttal D. (1998). A cross-cultural study of young children's mapping abilities. Transactions of the Institute of British Geographers, 23, 269-277.

[3] Clements, D. \& Sarama, J. (2009). Learning and teaching Early Math. The Learning Trajectories Approach. New York and London: Routledge.

[4] DeLoache J. D. (2000). Dual representation and young children's use of scale Models. Child Development, 71(2), 329-338.

462 | P a g e 
[5] DeLoache J. D. \& Marzolf D. P. (1992). When a picture is not worth a thousand words: Young Children's understanding of pictures and Models. Cognitive Development, 7, 317-329.

[6] DeLoache J. D., Uttal D. H., \& Pierroutsakos S. L. (1998). The development of early symbolization: educational implications. Learning and Instruction, 8(4), 325- 339.

[7] Downs, R. M., Liben, L. S. \& Daggs, D. G. (1988). On education and geographers: The role of cognitive developmental theory in geographic education. Annals of Association of American Geographers, 78, 680-700.

[8] Goldin, G. A. \& Kaput, J. J. (1996). A joint perspective on the idea of representation in learning and doing mathematics. In L. Steffe, P. Nesher, P. Cobb, G. A. Goldin, and B. Greer (Eds.), Theories of Mathematical Learning (pp. 397-430). Hillsdale, NJ: Erlbaum.

[9] Kolukisa, E. A. \& Ocal, A. (2007). Children's representation of the route in a familiar environment. Bulgarian Journal of Science and Education Policy, 1(1), 83-91.

[10] Liben, L. S. \& Downs, R. M. (1993). Understanding Person-Scale-Map relations: Cartographic and Developmental perspectives. Developmental Psychology, 29(4), 739-752.

[11] Newcombe, N. S. \& Hutternlocher, J.(1992). Children's early ability to solve perspective-taking problems. Developmental Psychology, 28(4), 635-643.

[12] Pantidos, P. Valakas, K. Vitoratos, E. \& Ravanis, K. (2008). Towards applied semiotics: An analysis of iconic gestural signs regarding physics teaching in the light of theater semiotics. Semiotica, 172(1/4), 201-232.

[13] Piaget, J. \& Inhelder, B. (1956). The child's conception of space. London: Routledge and Kegan Paul.

[14] Pebone, R., Hummel, J. \& Holyoak, K. (2001). The use of diagrams in analogical problem solving. Memory and Cognition, 29(2), 214-221.

[15] Plester B., Richards J., Blades M. \& Spencer, C. (2002). Young children's ability to use aerial photographs as maps. Journal of Environmental Psychology, 22, 29-48.

[16] Ravanis, K. \& Papamichaël, Y. (1995). Procédures didactiques de déstabilisation du système de représentation spontanée des élèves pour la propagation de la lumière. Didaskalia, 7, 43-61.

[17] Ravanis, K. Papamichaël, Y. Koulaidis, V. (2002). Social marking and conceptual change: the conception of light for ten-year old children. Journal of Science Education, 3(1), 15-18.

[18] Ravanis, K. Zacharos, K. \& Vellopoulou, A. (2010). The formation of shadows: The case of the position of a light source in relevance to the shadow. Acta Didactica Napocensia, 3(3), 1-6.

[19] Shiakalli, M.A. \& Zacharos, K. (2012). The contribution of external representations in pre-school mathematical problem solving. International Journal of Early Years Education, 20(4), 315-331.

[20] Zacharos, K. (2005). Students' Measurement Strategies of Area'. Mediterranean Journal for Research in Mathematics Education, 4(2), 111-127.

[21] Zacharos, K. (2006). Prevailing Educational Practices of Area Measurement and Students' Failure'. Journal of Mathematical Behavior, 25(3), 224-239.

[22] Zacharos, K., Antonopoulos, K. \& Ravanis, K. (2011). Activities in mathematics education and teaching interactions. The construction of the measurement of capacity in preschoolers. European Early Childhood Education Research Journal, 19(4), 451-468.

[23] Zacharos, K. \& Koustourakis, G. (2011). A critical approach to school mathematical knowledge: The case of "realistic" problems in Greek primary school textbooks for seven-year-old pupils. Acta Didactica Napocensia, 4(1), 39-51. 